The Geneva Papers on Risk and Insurance, 19 (No. 73, October 1994) 496-502

\title{
Age Discrimination Against Older Workers in the European Union
}

\author{
by Elizabeth Drury*
}

\section{Summary}

This paper aims to define the concept of age discrimination, to illustrate examples of age discriminatory practices across the European Union, and to describe some positive public policy measures to combat age discrimination.

It draws on the results of the first European-wide study of age discrimination against older workers. ${ }^{1}$ National experts from 11 Member States of the EU examined various forms of age discrimination in their own country. More detailed information is needed, particularly on practices in the workplace, to provide a systematic overview of all discriminatory practices. This study, however, made a start in identifying some key issues.

\section{What is age discrimination against older workers?}

In examining what constitutes age discrimination against older workers, the problems related to older workers in employment are considered from the perspective of the individual older person.

Age discrimination can be defined as actions targetted at, or treatment of older workers on the basis of age alone, regardless of individual merit, which have a negative effect on the employment prospects of older workers or older job-seekers.

The justification for combatting age discrimination is based on the principles of citizen's rights and of equal opportunities for all groups of workers in the labour market. These same principles already apply to sex discrimination at work.

These basic principles also assume the individual's right to choose work or retirement. The early exit schemes offered on advantageous terms to many older workers in northern Europe are beneficial to those who choose and welcome early retirement. But many older (and middle-aged) workers are not prepared for an early exit at 50 or 55, in many cases on

* Elizabeth Drury is the European Union policy and political affairs consultant to Eurolink-Age. She is the author of: "Age Discrimination against older workers in the European Community", published by Eurolink-Age in September 1993. The report was funded by the European Commission as part of the 1993 European Year of Older People and Solidarity between Generations.

' Eurolink-Age; September 1993 
a reduced income. They may need, for financial or personal reasons, to continue working until official retirement age; but in practice they are often obliged, against their will, to leave work early.

Combatting age discrimination therefore means ensuring freedom of choice on the end of the working life, as well as equal opportunities on the labour market for those wishing to participate.

\section{Young versus older workers?}

There is some scepticism about the justification of defending older workers' rights at the expense of jobs for young people.

Actions to combat age discrimination should not, however, provoke a battle for jobs between the generations. Both groups have their particular employment problems. Examining and tackling the special problems of older workers does not mean ignoring the needs of young workers. The aim is to establish equality of opportunity for both groups to compete for jobs available on an individual basis.

Public policy measures versus employers' practices

Age discrimination is evident in both public policies and in the workplace. It is also clear that the discriminatory behaviour of employers is often rooted in specific public policy measures affecting older workers. The public authorities, as well as employers and trade unions, therefore need to be involved in this issue.

The Eurolink-Age study was a preliminary investigation and it focussed on public policies. In the absence of systematic studies on employers' and trade unions' practices the evidence presented was largely anecdotal. The European Foundation for Living and Working Conditions is now engaged in more detailed research into workplace attitudes towards age barriers in job recruitment and training, which should help to fill some of these gaps in knowledge.

The illustrations in this paper are therefore taken mainly from public policy measures identified in European Union countries.

\section{Age discriminatory measures}

Two types of discrimination were identified:

a) Direct discrimination

- The use of specific age limits to exclude older workers or older job-seekers from employment, recruitment processes or from employment measures such as re-training.

b) Indirect discrimination

- Measures which are not directly age-specific but which have a negative impact on older workers. For example, the widespread offers of "voluntary" redundancy made to older workers above a certain age.

- Apparently positive measures for older workers, which become negative in practice. For example, state subsidised "pre-retirement" allowances or similar benefits awarded to workers made redundant over a certain age: these in practice encourage employers to target older workers for redundancy.

a) Examples of direct discrimination

Obligatory early retirement

Such schemes exist in Greece, France, Italy and Portugal, where employers may oblige 
workers over a certain age (from 50/55 for men) to leave work. They remove any freedom of choice from the individual.

"Voluntary" early retirement schemes are also age discriminatory in principle, by targetting workers on the basis of age rather than ability. See below: Indirect Discrimination.

In Spain, another form of obligatory early retirement operates : any workers who are unemployed at age 60 are obliged to take an early pension. In so doing, they are forced to accept a $40 \%$ permanent reduction in their pension based on coefficient calculations.

\section{Upper age limits in recruitment}

Employers in all EC countries use upper age limits in both job advertisements and job descriptions. Only in France does legislation forbid this in principle in the private sector (Code du Travail 311-4) - but it is apparently hardly enforced.

In the public sector, six Member States have either no upper age limits (Denmark, the Netherlands, Portugal) or a limit of 50 (Belgium, Ireland, UK). The other national public sectors set limits of between 32 and 40 years, as do the EC institutions themselves.

Upper age limits in access to public employment measures

Age limits are set in several countries to exclude older workers or job-seekers from access to employment measures. These limits often apply over 10 years before the official retirement age. They appear to reinforce the assumption that once a job is lost at a certain age, there is no prospect of re-entering the labour market. Examples of age restrictions include :

Self employment subsidies:

Greece: $\quad$ upper age 50;

Denmark: upper age 60.

Recruitment subsidies to employers for long-term unemployed:

Netherlands: upper age 57.5;

Greece: $\quad$ upper age 60.

Rights to job offers from employment agencies:

Denmark: upper age 60.

Upper age limits in access to training

Three countries set specific age limits on access to training or re-training for unemployed workers. These exclude workers between 15 and 25 years before official retirement age.

Denmark: $\quad$ upper age 50 ;

Greece : $\quad$ upper age 46;

Italy: $\quad$ upper age 29.

The UK has recently (1994) raised its former age limits in this field to 63.

In Spain and Ireland, although no official age limits are set, figures show less than $1 \%$ of participants in training are aged over 55 .

\section{Exclusion from unemployment statistics}

In seven countries, (Belgium, Denmark, Germany, France, Ireland, Netherlands and UK) the payment of automatic benefits or pre-retirement allowances to older unemployed 
workers aged 55 or over excludes them from unemployment statistics - even though in most countries these benefits do not technically prevent them from seeking and taking employment and they are not drawing a pension.

\section{Discouragement of the older job-seeker}

The message delivered to the older job-seeker by these (mostly) public policy measures is discouraging: the state assumes that if a worker loses a job over a certain age he has no real prospect of re-entering the labour market and that there is no point in re-training to gain new skills for another job. The assumption is that he will automatically "retire".

From the perspective of age discrimination, such measures deny older job-seekers an equal opportunity to re-enter the labour market, and remove the free choice of individuals in respect of ending their working life.

\section{b) Examples of indirect discrimination}

Indirect discrimination is both more pervasive and more difficult to evaluate and to combat. It is essentially the product of society's attitudes towards older people.

\section{Older workers are targetted for "voluntary" redundancy offers}

Reports indicate that older workers are systematically targetted by employers for "voluntary" redundancies, although no public policy allows direct age targetting for redundancy. (The Netherlands stopped in early 1993 its former redundancy schemes allowing workers aged $55+$ to be targetted first).

So-called "voluntary" redundancy or early retirement is in practice often only voluntary in theory. Most countries report pressures on older workers from employers, work colleagues and family to encourage them to accept such offers. In practice, voluntary schemes then become obligatory.

Pre-retirement allowances or other special benefits are used to push older workers out

Apparently positive public policies can become negative in practice.

State subsidised pre-retirement allowances paid to workers from a certain age act as incentives for employers to target older workers for redundancy: this is the case in Belgium, Germany and France (although the French authorities have acted to discourage this).

In Greece, the entitlement for working mothers to an early pension at 55 (instead of 60 ) is used by employers to dismiss working mothers first - since they are legally allowed to dismiss workers at pensionable age.

\section{Lack of targetted measures to assist older unemployed}

Older redundant workers have particular needs in re-training and job-seeking, yet no country - except France - provides a range of measures targetted for their needs. The older unemployed fare badly compared with other special labour market groups, such as ethnic minorities, migrants, and women returners.

Even where employment schemes do not set direct age limits, in practice no priority is given to older applicants for re-training or for assistance in job-seeking. In many cases, public sector training available to older job-seekers is not pedagogically adapted to their age group and therefore much less effective. 


\section{Positive measures to combat age discrimination}

Measures to combat age discrimination should give older workers more employment opportunities, and more choice of whether to continue to work - or to retire. They should enable many to extend their working life, or to re-enter the labour market after redundancy, but they should not exclude the choice of early retirement.

Positive actions which public authorities could take in combatting age discrimination were identified, based on existing examples from some Member States. Actions could be taken in two stages:

- abolish direct age discriminatory measures;

- remove/reduce indirect discrimination.

\subsection{Abolish direct age discrimination}

Outlaw obligatory early retirement

Countries with obligatory early retirement schemes should make these voluntary, to avoid forcing workers into early exit. The Netherlands abolished its obligatory early retirement schemes in 1982 .

\section{Ban upper age limits in job advertisements}

Legislation to ban age limits in advertisements exists in France, limited to private sector employers. The Netherlands authorities are currently considering similar draft legislation. In the UK, there have been several public calls for similar measures, although the current government is opposed to legislation.

Public policy could be used here to influence employers' practices. Legislation alone would not change their recruitment practices, but it would provoke public debate on the issue and encourage employers to re-examine their personnel policy on age.

\section{Abolish upper age limits in public sector employment measures}

Existing upper age limits should be lifted in the fields of: self-employment subsidies; recruitment subsidies to employers; training for unemployed. The UK has recently (1994) lifted its former age limit of 60 (with priority only for those under 50) for adult training measures; the new upper age is now 63.

\subsection{Positive measures to combat indirect discrimination}

Two types of positive actions are needed to combat indirect discrimination and to help older workers to remain in or to re-enter the workforce:

- public policy measures targetted for older workers; and

- positive influence on and dialogue with the social partners to change attitudes in the workplace.

i) Public policy measures

Targetted employment promotion measures for older workers need not be a drain on public resources, if they resulted in older workers remaining productive in the labour market instead of dependent on state benefits for the last 5 to 10 years before official retirement age. 
There is need for full cost-benefit analysis of the financial implications of providing targetted assistance to help the older unemployed back into the labour market, and of their chances of finding permanent employment at this stage.

\section{Employment promotion measures}

Among EC countries, only France has introduced a range of targetted employment promotion measures for older workers. These include :

- measures to discourage early exit, by imposing financial penalties on employers, legally protecting certain workers aged 50-54 from redundancy, and providing incentives for company schemes to keep older workers at work ;

- measures to assist re-integration into the labour market; by providing $100 \%$ exemption from employers' contributions for recruitment of unemployed aged $50+$ until pensionable age; by providing targetted assistance by employment agencies to help unemployed people over 50 seek another job; by giving priority to unemployed workers aged $50+$ in employment measures for long-term unemployed.;

- support for training: financial incentives for employers to train workers aged $45+$.

Other employment promotion measures are rare:

- Belgium, Germany and Spain ${ }^{2}$ each have one employment scheme targetted at older workers. In Germany, wage subsidies of up to $75 \%$ for up to 8 years are paid for recruitment of unemployed aged $50+$. In Spain, subsidies are paid to employers recruiting unemployed aged $45+$, including $50 \%$ exemption from social security contributions.

\section{Protection against redundancy/dismissal}

Some protection against redundancy or dismissal based solely on age exists in Germany, Greece, Spain, France, Italy, and the Netherlands. It will soon also exist in Ireland, where the 1977 Unfair Dismissals Act has recently been amended to include age as a criterion for unfair dismissal for workers aged $50+$.

\section{ii) Dialogue with employers and trade unions}

The United Kingdom has set up a special Advisory Group on older workers reporting to its Employment Department. This group has examined the potential for older workers in the labour market and has launched an initiative - "Getting On" - to persuade employers in particular of the value of employing older workers, with a code of conduct to combat ageism in the workplace. The UK is opposed to legislative measures.

France has also set up a working group on older workers and created a special research centre on age and the workforce "Centre de Recherches et d'Etudes sur l'Age et les Populations au Travail (CREAPT)”.

\section{Conclusions}

Actions to combat age discrimination should be based on the interests and citizen's rights of older workers, to promote their equal opportunities in the labour market and their right to choose work or retirement.

These actions, if successful, will allow more older workers to stay longer in the workforce or to extend their working lives. This will be in the future interest of governments,

2 The UK also operates one local scheme, limited to a specific region, of one-off recruitment subsidies to employers taking on unemployed workers aged over 50 . 
in view of the increasing financial burden of social security systems and the demographic trends bringing larger numbers of older people in the next century.

It is therefore possible that the interests of older people who want to continue working may coincide with the financial needs of governments in the coming years and produce more positive actions to combat age discrimination in employment. Changing the attitudes of employers, however, remains the key to any real improvement in employment opportunities for older workers. Employers will need to be persuaded of the economic benefits to them of an older workforce - and both governments and today's middle-aged workers need to recognise this. 